\title{
Mouse Embryonic Fibroblasts Acquire Sarcomagenesis Potential after Differentiating into Insulin-Producing Cells
}

Gupta $\mathrm{A}^{1 \dagger}$, Kurtovic $\mathrm{S}^{1 \dagger}$, Ng TT ${ }^{1 \dagger}$, Tsuyoshi $\mathrm{T}^{1}$, Narwani $\mathrm{K}^{2}$, Biancotti $\mathrm{JC}^{6}$, Spurka $\mathrm{L}^{3}$, Funari $\mathrm{V}^{3,5}$, Balzer $\mathrm{B}^{4}$, Talavera-Adame $\mathrm{D}^{1,2^{\star}}$ and Dafoe DC ${ }^{1,2}$

${ }^{1}$ Comprehensive Transplant Center, Department of Surgery, USA

${ }^{2}$ Board of Governors Regenerative Medicine Institute, USA

${ }^{3}$ Medical Genetics Institute and Genomic Core, USA

${ }^{4}$ Anatomic Pathology and Dermatopathology, Cedars-Sinai Medical Center, 8700 Beverly BIvd, Los Angeles CA, USA

${ }^{5}$ David Geffen Schools of Medicine at UCLA, Division of Medical Genetics and Biomedical Sciences, Los Angeles, CA, USA

${ }^{6}$ Zilkha Neurogenetic Institute, Keck School of Medicine of the University of Southern California, Los Angeles, CA, USA

tContributed equally to this work

\begin{abstract}
An abundant source of insulin-producing cells would enhance the success of islet transplantation for treatment of diabetes. Insulin-producing cells can be derived from human fibroblasts which acquired a mesenchymal stem cell (MSC) phenotype. However, these MSCs are able to give rise sarcomas after transformation. Our aim was to investigate whether mouse embryonic fibroblast (MEF) acquire sarcomagenesis potential after differentiating to insulinproducing cells. We derived insulin-producing cells from a MEF cell line MMMbz. After differentiation, the cells were labeled with green fluorescent protein (GFP) driven by rat insulin promoter (INS-GFP) for cell isolation, expansion and characterization by immunocytochemistry (ICC), quantitative RT-PCR (qRT-PCR), and genetic microarrays. These cells were then FACS sorted and transplanted under the kidney capsule of SCID mice to evaluate cell behavior. Grafted cells were analyzed by IHC. MMMbz expressed platelet-derived growth factor receptor alpha (PDGFR- $\alpha$ ) and nestin. After differentiation, higher expression of beta-cell markers were found in sorted cells compared to non-sorted cells. Genetic microarray corroborated the expression of pancreatic and mesenchymal markers along with activation of cancer pathways. Within 30 days after transplantation, all grafted mice developed undifferentiated sarcomas that impaired further assessments of insulin-producing cell function. Therefore, insulin-producing cell lines can be derived in vitro from mouse embryonic fibroblasts that behave as MSCs but sarcomagenesis potential may be conferred by a subpopulation of transformed cells.
\end{abstract}

Keywords: Embryonic; Fibroblasts; Insulin; Sarcomagenesis

\section{Introduction}

The defects in insulin synthesis and the effects of diabetes result in devastating complications, which include nephropathy, retinopathy, stroke, and heart attack [1]. In an attempt to treat Type 1 diabetes mellitus (T1DM) by cellular transplantation, human insulin-producing cells have been derived [2]. Although these cells are promising for potential therapeutic uses, a major problem remains in the generation of expandable cell lines and safety after transplantation. Human pluripotent stem cells (hPSCs) and mesenchymal stem cells (MSCs) have been used as a potential source of insulin-producing cells [3-10]. MSCs are multipotent fibroblast-like cells expressing endoglin (CD105) and 5 '-nucleotidase (CD73) $[11,12]$. However, these phenotypes are also shared by fibroblasts [13]. Fibroblast differentiation to several cell lineages has been described [14,15]. For instance, human dermisderived fibroblasts have been differentiated into insulin-producing cells $[16,17]$. Additionally, human skin fibroblasts exposed to a DNA methyltransferase inhibitor (5-azacytidine) followed by a specific protocol for pancreas differentiation can give rise to glucose-responsive insulin-producing cells [18]. This fact confirms that insulin-producing cells can be originated from mesoderm-derived cells [15]. Furthermore, nestin, an intermediate filament expressed mostly in nerve cells (ectoderm-origin cells), has been used as a marker of pancreatic precursors to derive insulin-producing cells from mouse embryonic stem cells [19]. However, the fraction of differentiated cells that stained positive for insulin has been very low [20]. In another approach, interactions of embryonic stem cells with endothelial cells have proof to be promising for beta-cell derivation from PSCs [21-24]. However, autologous transplantation constitutes an attractive alternative using cells from the same patient such as fibroblasts. These cells can be expanded in culture and cell lines can be derived but fibroblasts plasticity as well as oncogenic potential should be investigated in detail before considering these cells for regenerative medicine.

\section{Materials and Methods}

\section{Cells and reagents}

Mouse embryonic fibroblasts (MMMbz) (Harvard Medical School, Boston, MA) [25] were grown at $37^{\circ} \mathrm{C}$ under $5 \% \mathrm{CO}_{2}$ in DMEM-H (Invitrogen, Carlsbad, CA) supplemented with $10 \%$ BCS (Hyclone, Novato, CA). To induce differentiation, confluent monolayers were treated according to a published protocols $[3,4]$. Differentiated cells were maintained in DMEM-H supplemented with 10\% FBS (Omega Scientific Inc., Tarzana, CA), $200 \mathrm{mM} \mathrm{L}$-alanyl-L-glutamine, $200 \mathrm{mM}$ MEM non-essential amino acids, $200 \mathrm{mM}$ sodium pyruvate, and 100 $\mu \mathrm{M}$ beta mercaptoethanol. Mouse insulinoma cell line (Beta-TC-6)

*Corresponding author: Dodanim Talavera-Adame, M.D., Ph.D. Assistan Professor, Comprehensive Transplant Center, Department of Surgery and Board of Governors Regenerative Medicine Institute, Cedars-Sinai Medical Center 8700 Beverly Blvd., A8104-R, Los Angeles, CA 90048, USA, Tel: (310) 248-6698; E-mail: Dodanim.Talavera@cshs.org

Received July 28, 2015; Accepted September 02, 2015; Published September 08, 2015

Citation: Gupta A, Kurtovic S, Ng TT, Tsuyoshi T, Narwani K, et al. (2015) Mouse Embryonic Fibroblasts Acquire Sarcomagenesis Potential after Differentiating into Insulin-Producing Cells. J Stem Cell Res Ther 5: 302. doi:10.4172/2157 7633.1000302

Copyright: ( 2015 Gupta A, et al. This is an open-access article distributed under the terms of the Creative Commons Attribution License, which permits unrestricted use, distribution, and reproduction in any medium, provided the original author and source are credited. 
and mouse embryonic fibroblasts (MEF) (ATCC, Manassas, VA) were maintained in DMEM-H supplemented with 15\% FBS (Omega Scientific Inc., Tarzana, CA) and used as positive and negative controls respectively.

\section{Immunocytochemistry (ICC)}

Differentiated cells were fixed with paraformaldehyde $4 \%$ (Polysciences, Inc., Warrington, PA) and permeabilized with $0.3 \%$ triton X-100 in PBS. After a blocking solution (PBS/5\% BSA) the cells were exposed overnight to primary and secondary antibodies (Supplementary Table 1a). Anti-Nkx6.1 was developed by Ole D. Madsen and obtained from the Developmental Studies Hybridoma Bank developed under the auspices of the NICHD and maintained by the University of Iowa, Iowa City, IA 52242. Images were acquired with a multi-purpose zoom microscope (Nikon AZ 100, USA) attached to a DS-Qil High-sensitivity CCD Camera (http://www.nikon.com/) and analyzed using an imaging software of NIS-Elements AR 3.10 (Nikon Instruments, Melville, N.Y.) and ImageJ 1.30v (Wayne Rasband National Institutes of Health; USA).

\section{Plasmid Construction and Transfection}

Dr. Benvenisty (Cedars-Sinai Medical Center Stem Cell Institute, Los Angeles, CA) provided the expression vector composed of greenfluorescent protein driven by rat insulin promoter (INS-GFP). The construction and characterization of this plasmid has been previously reported [7]. Following the differentiation protocol, the cells were plated at $5 \times 10^{4}$ cells $/ \mathrm{mL}$ in 6 -well plates. At $60 \%$ confluence, the transfection was performed using a transfection kit according to manufacturer instructions (Polyplus-Tranfection Inc., New York, NY).

\section{FACS and sorting}

$5 \mathrm{X} 10^{5}$ differentiated and transfected cells were harvested at passage (P3). A single cell suspension was prepared in $0.5 \mathrm{~mL}$ and analyzed by FACS. The INS-GFP positive cells were sorted and re-plated in $10 \mu \mathrm{g} / \mathrm{mL}$ laminin- 1 and $10 \mu \mathrm{g} / \mathrm{mL}$ collagen-IV (Rand D Systems, Inc., Minneapolis, MN) pre-coated dishes.

\section{Quantitative real time RT-PCR (qRT-PCR) analysis}

Total RNA isolated from mouse pancreas (Clontech, Mountain View, CA) and differentiated insulin-producing cells before and after sorting using RNAeasy mini kit (Qiagen, Valencia, CA) were used for cDNA synthesis. After cDNA synthesis, using a QuantiTect Reverse Transcription kit (Qiagen, Valencia, CA), quantitative realtime PCR analysis was performed using a SYBR Green RT-PCR kit (Qiagen, Valencia, CA) and the Light Cycler instrument (AB Applied Biosystems, Foster City, CA). PCR cycle conditions as well as the forward and reverse primers used (all sequences are 5'-3') are included in the Supplementary Tables $1 \mathrm{~b}$ and 1c. Negative controls were included in each analysis. All samples were run in triplicate and PCR products were observed by gel electrophoresis on $2 \%$ agarose ethidium bromidestained gels. Analysis was performed using 7300 Sequence Detection Software (SDS) Version 1.3 (Applied Biosystems, Foster City, CA). A standard curve was obtained by running a gene-plasmid with a known copy-number value (based on its molecular weight). The values were normalized relative to GAPDH expression.

\section{Karyotyping}

Cell samples of INS-GFP expressing cells at early (P3 - P10) and late passages (P11 - P20) were analyzed at Cell Line Genetics (Madison, WI) for karyotyping.

\section{Cell cycle and proliferations assays}

The incorporated bromodeoxyuridine (BrdU) was detected using a BrdU Flow kit according to the manufacturer's instructions (BD Pharmingen, Rockville, MD) in INS-GFP expressing cells at early (P3 - P10) and late (P11 - P20) passages. The level of cell-associated BrdU coupled with a dye that binds to total DNA such as 7amino-actinomycin $\mathrm{d}$ (7-AAD) was measured by flow cytometry. With this combination, two-color flow cytometry analysis allowed us to recognize cells actively synthesizing DNA and the corresponding cell cycle.

\section{Microarray}

RNA was assessed for quantity and quality using NanoDrop 8000 Spectrophotometer and Agilent 2100 Bioanalyzer respectively. All samples scored 10 (highest score) for RNA Integrity by the bioanalyzer software. Details of the protocol are summarized in supplementary Table 1d.

\section{Animal transplantation}

Animal experiments were approved by The Cedars-Sinai Animal Care and Use Committee (IACUC). Confluent monolayers of sorted INS-GFP expressing cells were harvested at passage 5. The cell pellet with $3-5 \times 10^{6}$ cells was placed on ice. Severe combined immunodeficient (SCID) male mice Prkdc were used at 6-8 weeks of age. With the mouse under anesthesia, a $2.5 \mathrm{~cm}$ incision was made above the left kidney. INS-GFP expressing cells were transplanted under the kidney capsule of the left kidney using a $1 \mathrm{~mL}$ insulin syringe with an ultra-fine needle $(1 / 2$, $30 \mathrm{G})$. The fascia was re-approximated with suture and the skin was then closed with a subcuticular suture. In control mice, PBS was injected under the capsule of the left kidney.

\section{Glucose and insulin measurements}

Blood samples were collected from mice four times at one-week intervals during cell engraftment. Mice serum samples were subjected to ultrasensitive ELISAs for mouse insulin detection (Mercodia, Winston Salem, NC). The detection limit for ELISA assay was 0.07 $\mathrm{mU} / \mathrm{L}$ that corresponds to $2.4 \mathrm{ng} / \mathrm{mL}$ or $0.42 \mathrm{pmol} / \mathrm{L}$. The glucose levels were measured using blood glucose test strips and a blood glucose meter (Bayer Health Care LLC, Mishawaka, IN).

\section{Immunohistochemistry}

The kidneys were removed 30-60 days after cell transplantation for immunohistochemistry (IHC) analysis. Paraffin sections of $7 \mu \mathrm{m}$ for Hematoxylin and Eosin (Hand E), insulin (Dako, Carpinteria, CA), glucagon , somatostatin (abcam, san Francisco, CA), smooth muscle actin (SMA), desmin, keratin AE1/AE3, S100 protein (Leica Microsystems Inc., Buffalo Grove, IL) and frozen sections of $7 \mu \mathrm{m}$ for Hand E, histone H2A (abcam, Cambridge, MA) were performed using primary antibodies. For paraffin sections, microwave heat-induced epitope retrieval, and the automated detection systems such as Leica BOND-MAX (Leica Microsystems Inc, Buffalo Grove, IL) or DAKO autostainer (Dako North America Inc., Carpinteria, CA) were used. For frozen section staining previous protocols were used [21].

\section{Statistical analysis}

Data are expressed as mean \pm standard error of absolute quantification of gene expression values from three independent experiments. Then, the values were assessed by Student's $t$-test using GraphPad Prism software (GraphPad Software, Inc. La Jolla, CA). 
Citation: Gupta A, Kurtovic S, Ng TT, Tsuyoshi T, Narwani K, et al. (2015) Mouse Embryonic Fibroblasts Acquire Sarcomagenesis Potential after Differentiating into Insulin-Producing Cells. J Stem Cell Res Ther 5: 302. doi:10.4172/2157-7633.1000302

\section{Results}

MMMbz can be differentiated in vitro into insulin-producing cells

A protocol to generate insulin-producing cells was carried out in MMMbz [3]. We suspected that MMMbz had a MSC subpopulation and assessed expression of MSC markers. We found very low expression of CD44 and higher expression PDGFR-alpha in these cells before differentiation (Figures 1a and 1b). Some cells also expressed nestin, a neuronal progenitor marker (Figure 1c). Isotype controls are shown in the inset of Figure 1a. After differentiation, some cells expressed pancreatic progenitor markers such as neurogenin-3 $(\mathrm{Ng} 3)$ (Figures 1d, 1e [yellow arrows] and 1f), homeobox protein Nkx6.1 (Figures 1g,
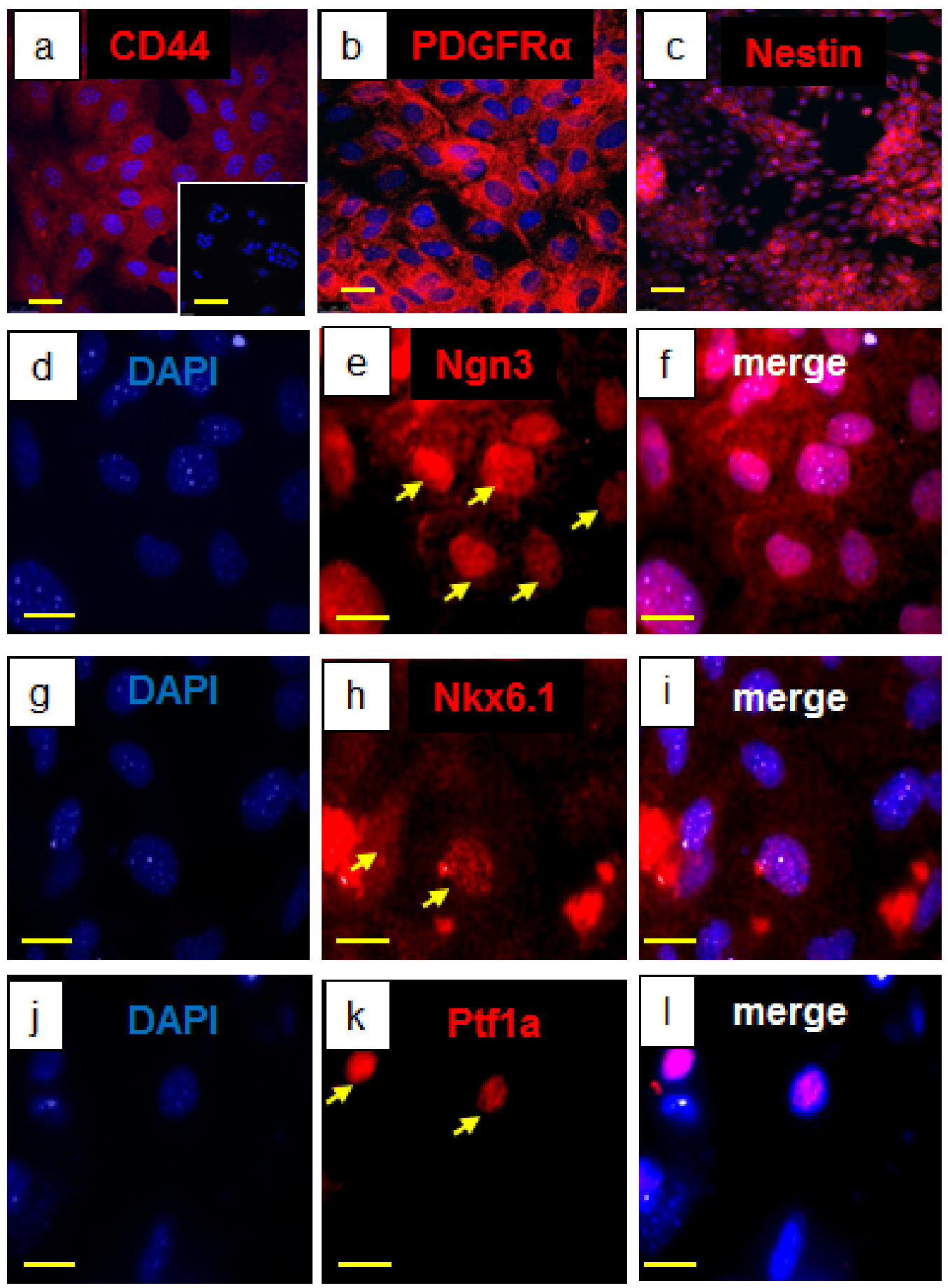

Figure 1: Marker expression in MMMbz before and after differentiation. Before using the differentiation protocol, MMMbz cells expressed (a) CD44 (red), (b) PDGFRa (red), and (c) nestin (red). The inset in (a) shows isotype controls. After differentiation, the cells expressed (e) Ngn3, (h) Nkx6.1, and (k) Ptf1a. (d, g, j) DAPI staining. $(f, i, l)$ Merged images. (a, b) bar $=25 \mu \mathrm{m}$. Inset in (a), bar $=100 \mu \mathrm{m}$. (c) bar $=100 \mu \mathrm{m}$. (d to l) bar $=10 \mu \mathrm{m}$. 
Citation: Gupta A, Kurtovic S, Ng TT, Tsuyoshi T, Narwani K, et al. (2015) Mouse Embryonic Fibroblasts Acquire Sarcomagenesis Potential after Differentiating into Insulin-Producing Cells. J Stem Cell Res Ther 5: 302. doi:10.4172/2157-7633.1000302

1h [yellow arrows] and 1i), and pancreas transcription factor 1-alpha (Ptfla) (Figures 1j, 1k [yellow arrows] and 1l).

Fibroblasts-derived insulin-producing cells can be transfected, isolated, and expanded

Before differentiation, MMMbz had a typical morphology (Figure 2a). After differentiation, these cells exhibited epithelial-like morphology (Figure $2 b$ ). These cells were transfected with INS-GFP expression vector (Figures $2 \mathrm{c}$ and $2 \mathrm{~d}$ ). About $12 \%$ of the cells were INSGFP positive evaluated by FACS (not shown). These cells were then sorted and re-plated (Figures 2e and 2f). They became a subconfluent monolayer after 5 days in culture (Figure $2 \mathrm{~g}$ ). The cells were expanded up to passage 20. Transfected Beta-TC-6 cells and MEFs were used as positive (Figure $2 \mathrm{~h}$ ) and negative (Figure $2 \mathrm{i}$ ) controls of INS-GFP expression respectively.

\section{INS-GFP expressing cells co-expressed beta-cell markers}

To evaluate beta-cell marker expression in sorted INS-GFP expressing cells, we plated these cells at low density. Under these culture conditions, elongation was observed in most of the cells (Figure 3). At higher magnification, the expression of INS-GFP was evident (Figure 3a). Non-specific staining was observed using isotype controls (Figures
$3 \mathrm{~b}$ and $3 \mathrm{c}$ ). INS-GFP expressing cells co-expressed insulin (Figures $3 \mathrm{~d}$, $3 \mathrm{e}$ and $3 \mathrm{f}$ ), proinsulin (Figures $3 \mathrm{~g}, 3 \mathrm{~h}$ and $3 \mathrm{i}$ ), and PDX-1 (Figures $3 \mathrm{j}$, $3 \mathrm{k}$ and $3 \mathrm{l}$ ). Sorted INS-GFP expressing cells were also positive to antimacro H2A.2 antibody (not shown) to visualize the Barr body (the inactive chromosome in dormant female cells).

To quantify the expression of pancreatic markers, qRT-PCR was carried-out on INS-GFP expressing cells. Insulin, PDX-1, and Ngn3 were evaluated. In addition, glucose sensing mechanisms by the expression of GLUT2, GKS, the inward-rectifier potassium ion channel 6.2 (Kir6.2) and sulfonylurea receptor (SUR1). The expression of insulin, PDX-1, Ngn3, GLUT2, GKS, and SUR1 was significantly higher in sorted cells compared to non-sorted cells (Figures $4 \mathrm{a}$ and $4 \mathrm{~b}$ ). qRT-PCR products were observed by electrophoresis and compared to the same marker expression in adult mouse pancreas (Figure 4c). No expression of STT and GCG was detected in INS-GFP expressing cells (Figure 4c).

\section{INS-GFP exhibited chromosomal abnormalities and altered cell cycle}

After cell differentiation and sorting, we analyzed the cell cycle and proliferation at early (P3-P10) and late (P11-P20). At early passages, $85 \%$ of the cells were in phase G0/G1 and $2.5 \%$ in phase $\mathrm{S}$ of the


Figure 2: (INS-GFP) expression and FACS sorting of differentiated insulin-producing cells. (a) Undifferentiated MMMbz. (b) Differentiated insulin-producing cells. (c) Differentiated cells transfected with INS-GFP expression vector. (d) INS-GFP-expressing cell (green). (e, f) Sorted INS-GFP-expressing cells plated on pre-coated plates observed with phase contrast microscope or fluorescent microscope respectively. (g) Higher magnification of INS-GFP expressing cells (green) co-stained with DAPI (blue). (h) $\beta$-TC-6 or (i) MEFs transfected with INS-GFP.

$(\mathrm{a}-\mathrm{f}, \mathrm{h}, \mathrm{i}) \mathrm{Bar}=100 \mu \mathrm{m}$. (g) Bar $=10 \mu \mathrm{m}$. 
Citation: Gupta A, Kurtovic S, Ng TT, Tsuyoshi T, Narwani K, et al. (2015) Mouse Embryonic Fibroblasts Acquire Sarcomagenesis Potential after Differentiating into Insulin-Producing Cells. J Stem Cell Res Ther 5: 302. doi:10.4172/2157-7633.1000302
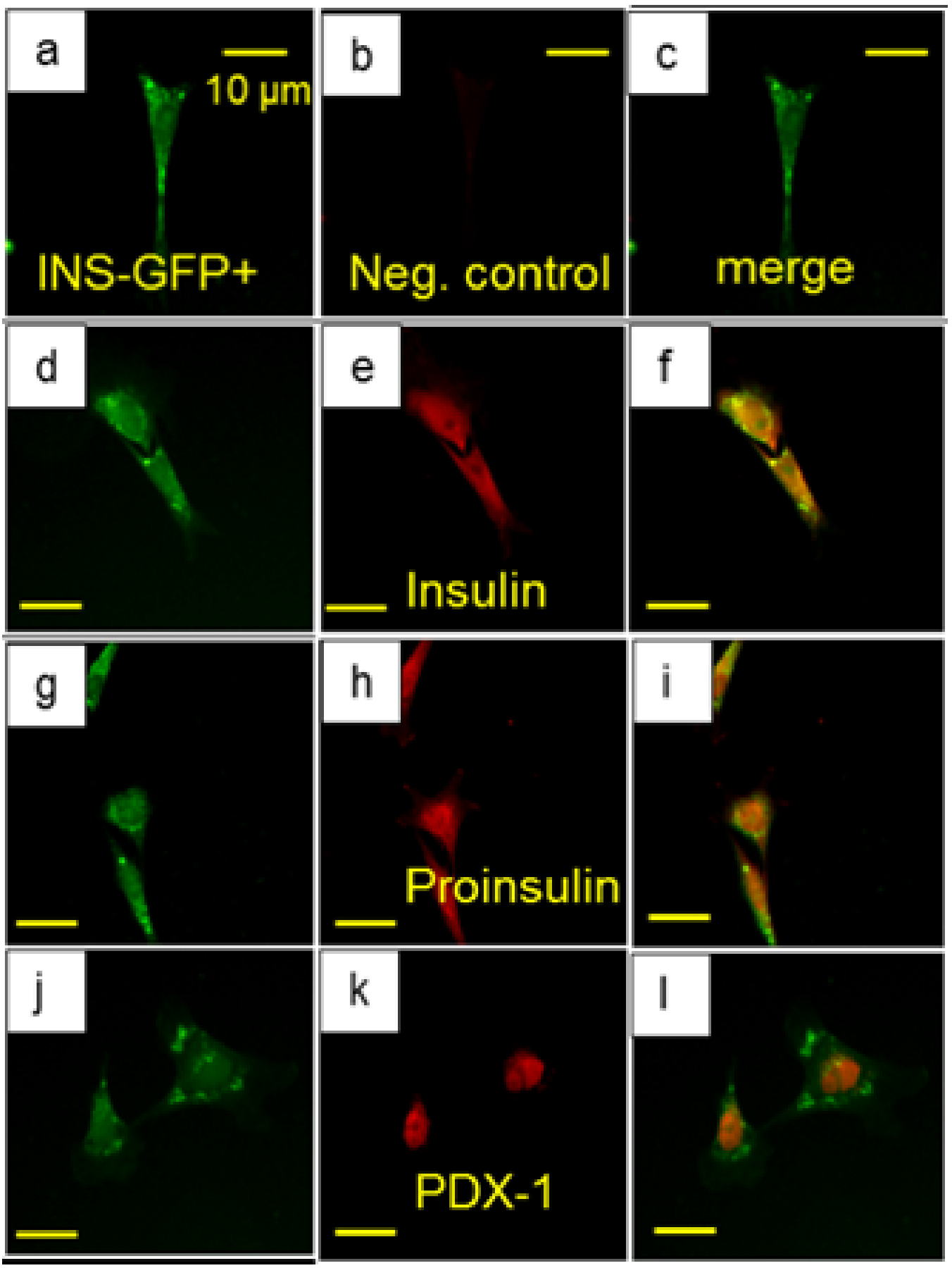

Figure 3: Expression of beta-cell markers in INS-GFP expressing cells at passage 3 after sorting. (a) Expression of INS-GFP. (b) Negative control stained with isotype control antibodies. (d, g, j) INS-GFP expressing cells that co-express (e) insulin, (h) proinsulin, and (k) PDX-1. (c, f, i, l) Merged images. Scale bar = 10 um.

cell cycle in contrast to $16.7 \%$ and $80 \%$ respectively for late passages (Supplementary Figures 1a and 1b). Chromosomal abnormalities such as the presence of 75 chromosomes with three to five copies of each autosome (chromosomes 1-19) (Supplementary Figures 1c and 1d) were identified both at early and late passages.

\section{Grafted mice developed tumors that contained islet-like} structures

Glucose and insulin blood levels were measured in grafted mice at 30-days post-transplantation. Either control or transplanted mice had normal insulin and blood glucose levels (not shown). However, $100 \%$ of these mice developed visible internal tumors located close under the surgical incision. All tumors were adjacent and adherent to the kidney capsule and were carefully dissected under stereoscope to avoid inclusion of surrounding organs. Grossly, the average size and weight of the amorphous tumors were $3.75 \times 2.5 \mathrm{~cm}$ and 3.5 grams respectively (not shown). The IHC analysis revealed islet-like clusters positive for insulin (arrows in Figure 5a), GCG (arrowheads in Figure 
(a)

(b)
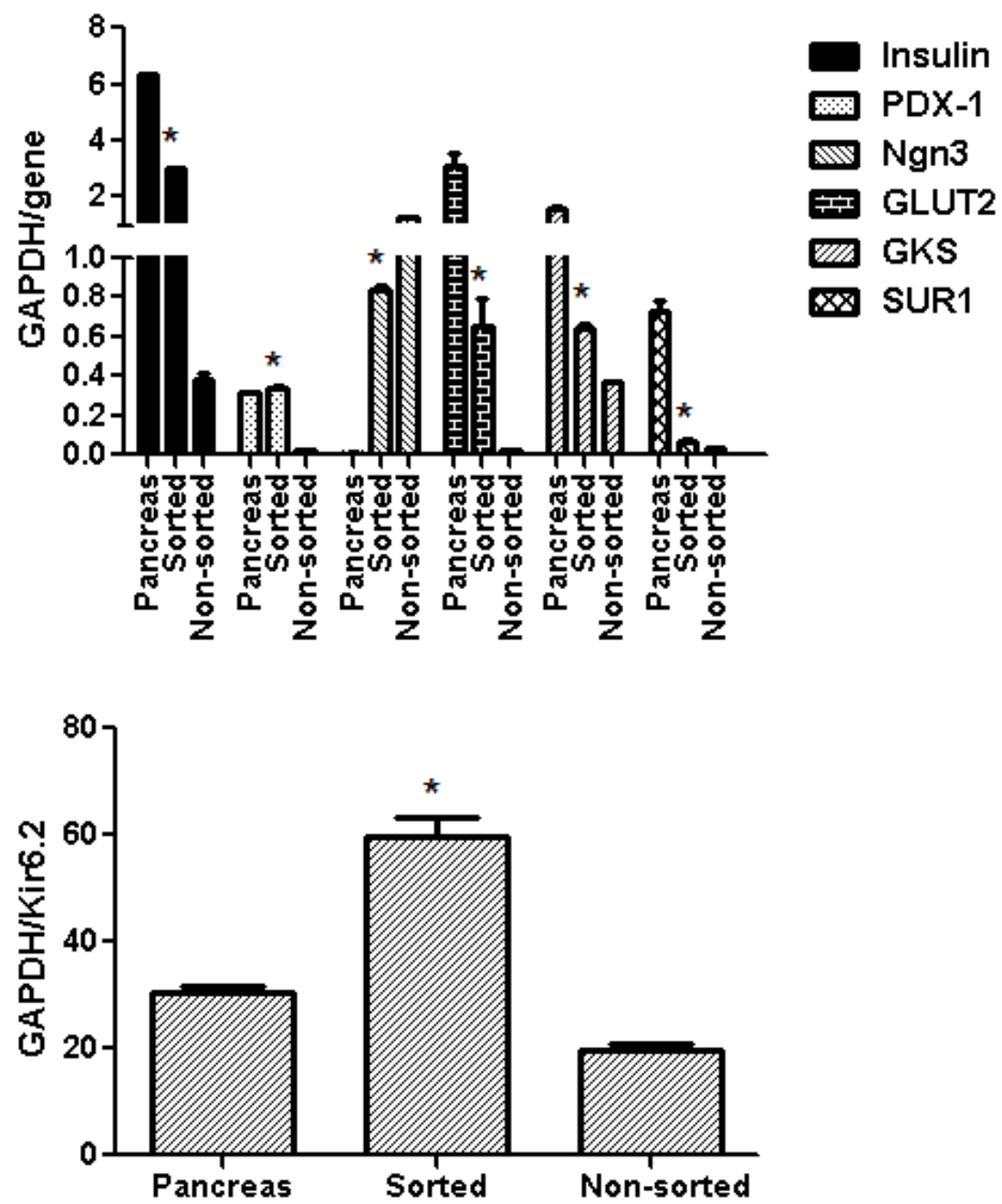

(c)

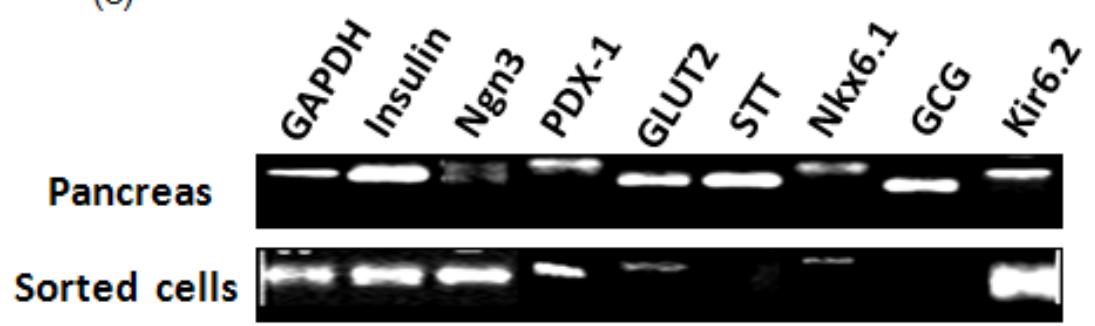

Figure 4: Quantification of beta-cell genes in non-sorted and sorted INS-GFP-expressing cells by qRT-PCR. (a) Expression of insulin, PDX-1, Ngn3, GLUT2, GKS, and SUR1. (b) Expression of Kir6.2 indicated in a separate graph because of the amount of this marker. (c) PCR products observed by gel electrophoresis. ${ }^{*} \mathrm{P}<0.05$ in sorted vs. non-sorted cells.

$5 \mathrm{~b}$ located close to the kidney capsule), and STT (arrow in Figure $5 \mathrm{c}$ ). Some clusters were positive for these three markers (Figure $5 \mathrm{~d}$ [insulin], Figure 5e [glucagon], and Figure 5f [somatostatin]). Severe deterioration in mice condition prompted us to perform euthanasia in these animals. In some islet-like clusters the expression of insulin (arrow in Figure 5g) was much lower than the expression of GCG
(Figure 5h) or STT (Figure 5i). In other areas of the tumor, structures that resembled acini and cavities linen by epithelial-like cells were also found (Figures $5 \mathrm{j}, 5 \mathrm{k}, 5 \mathrm{l}$ and $5 \mathrm{~m}$ ) with isolated insulin positive cells (arrow in Figure 5k). Ki67 was expressed in some but not all cells of the tumor (arrows in Figure 5n), Islet-like clusters positive for insulin also expressed Ki67 (Figure 5o) suggesting cell proliferation. Normal mouse 
Citation: Gupta A, Kurtovic S, Ng TT, Tsuyoshi T, Narwani K, et al. (2015) Mouse Embryonic Fibroblasts Acquire Sarcomagenesis Potential after Differentiating into Insulin-Producing Cells. J Stem Cell Res Ther 5: 302. doi:10.4172/2157-7633.1000302

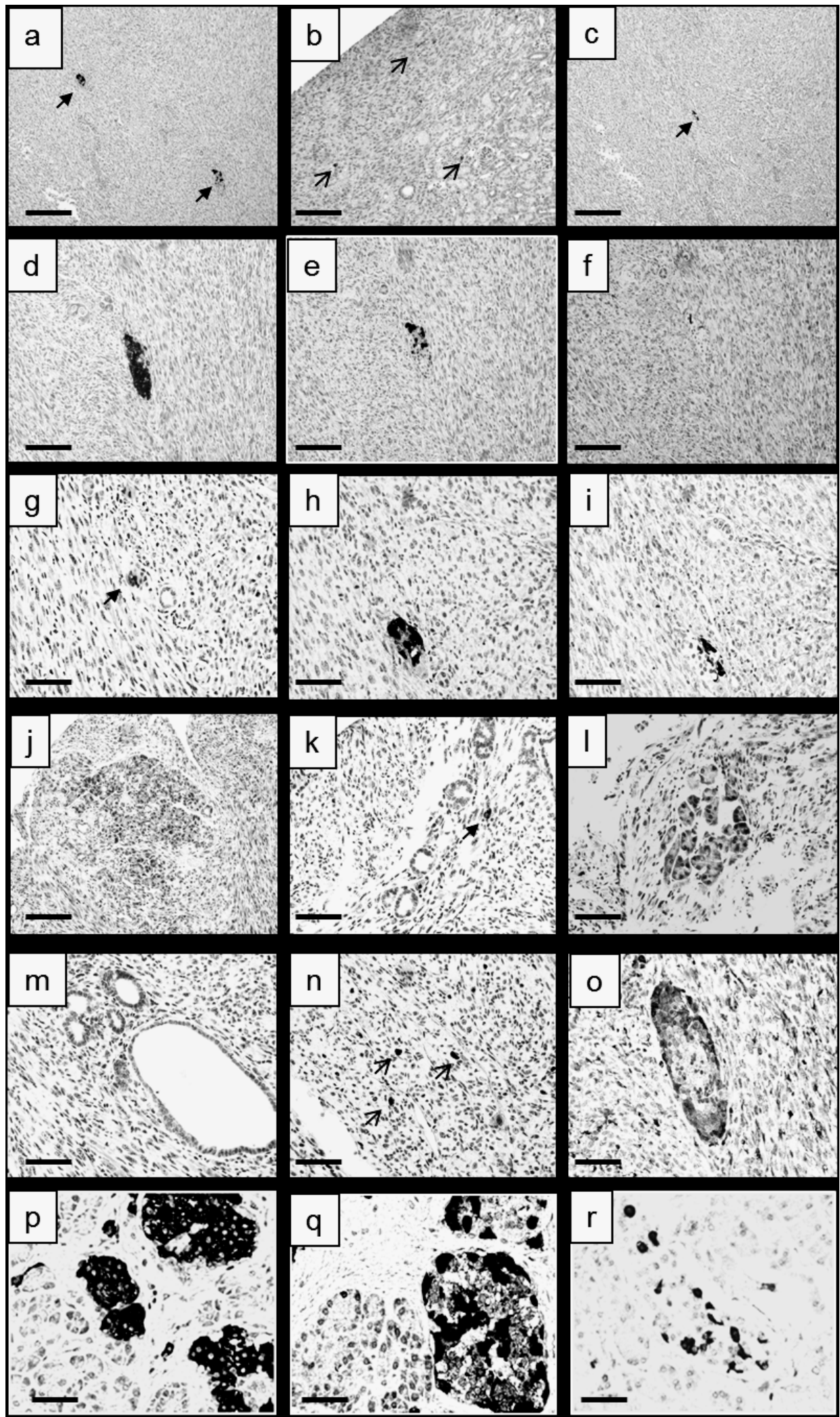

Figure 5: Immunohistochemical analysis of the INS-GFP cells engrafted under the kidney capsule of SCID mice. (a) Islet-like clusters that expressed insulin (arrows). (b) Cells close to the kidney capsule that expressed GCG (arrows). (c) Clusters that expressed STT (arrow). (d) Higher magnification of islet-like clusters showed in "a". (e) The same cluster that expressed GCG and (f) STT. (g) Different cluster that expressed insulin, (h) GCG, and (i) STT. (j) Acini-like structure. (k) Epithelial-like cells with insulin positive (black) cells (arrow). (I) Acini-like structure in a different field. (m) Cavities lined by epithelial-like cells. ( $\mathrm{n}$ ) Cells that expressed Ki67. (o) Islet-like cluster that co-expressed insulin (not shown) and Ki67 (black). (p) Normal mouse islet that express (p) insulin, (q) GCG, and (r) STT. (b, d, e, f, j, k, I) Bar = $250 \mu \mathrm{m}$. $(\mathrm{g}, \mathrm{h}, \mathrm{i}, \mathrm{m}, \mathrm{n}, \mathrm{o}, \mathrm{p}, \mathrm{q}, \mathrm{r})$ Bar $=100 \mu \mathrm{m} .(\mathrm{a}, \mathrm{c})$ Bar $=400 \mu \mathrm{m}$. 
Citation: Gupta A, Kurtovic S, Ng TT, Tsuyoshi T, Narwani K, et al. (2015) Mouse Embryonic Fibroblasts Acquire Sarcomagenesis Potential after Differentiating into Insulin-Producing Cells. J Stem Cell Res Ther 5: 302. doi:10.4172/2157-7633.1000302

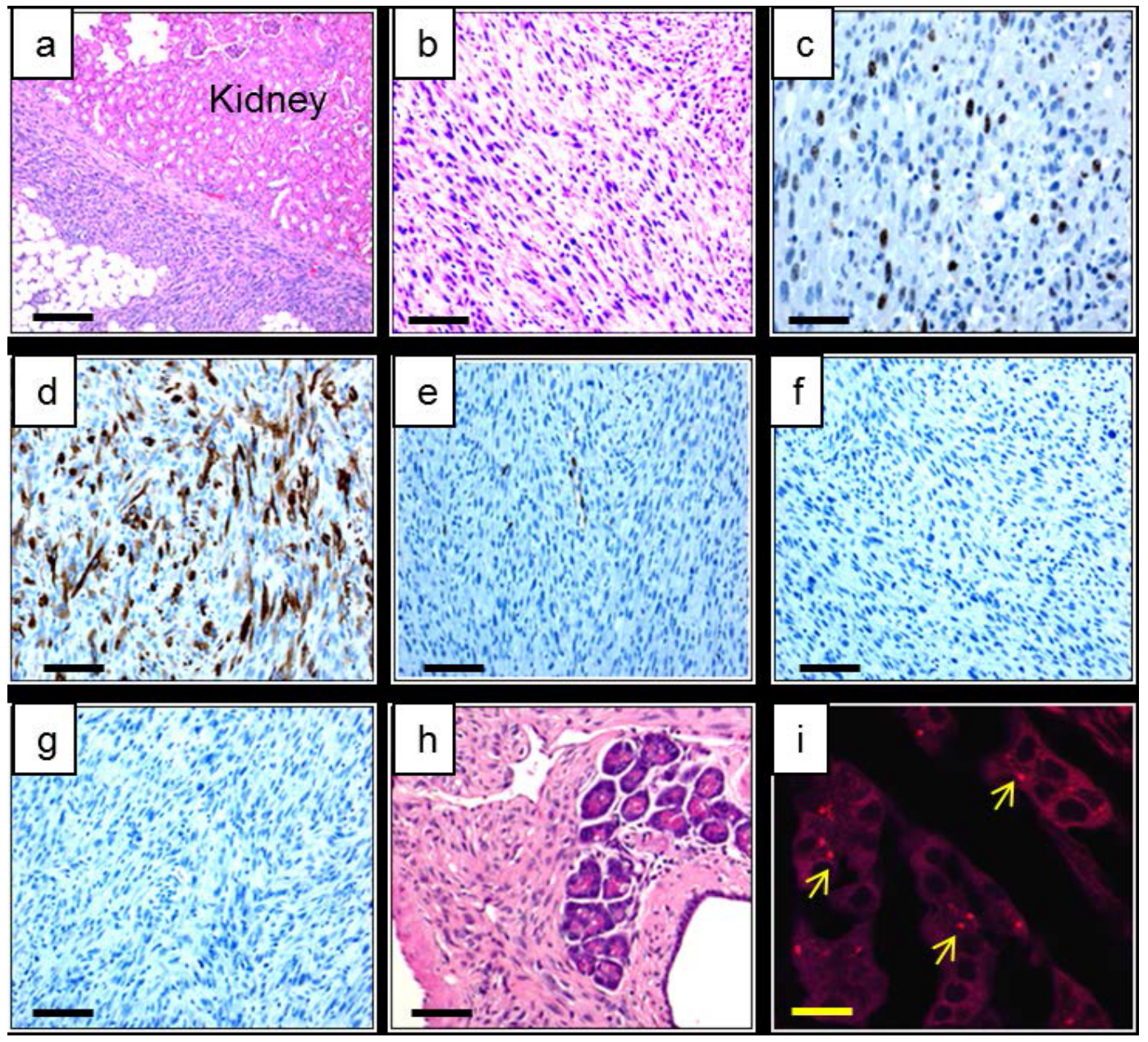

Figure 6: Immunohistochemical analysis of the tumor developed in engrafted SCID mice. (a) Hematoxylin and Eosin (H\&E) staining of the undifferentiated sarcoma close to the kidney capsule. (b) Higher magnification of the sarcoma stained with H\&E. (c) Tumor cells stained for Ki67, (d) smooth muscle actin (SMA), (e) desmin, (f) AE1/AE3, and (g) S-100 protein. (h) Acini-like structures found within the tumor stained with H\&E. (i) Higher magnification of these acini-like clusters stained also for anti-macro-H2A (Barr body). (a) Bar $=250$. $(b-h)$ Bar $=100 \mu \mathrm{m}$, (i) Bar $=25 \mu \mathrm{m}$.

pancreas was stained for insulin (Figure 5p), GCG (Figure 5q), and STT (Figure 5r) as positive control. Kidneys grafted with no differentiated MMMbz as well as non-grafted contralateral kidneys showed typical histology (not shown).

\section{Grafted mice developed undifferentiated sarcomas after INS- GFP expressing cell transplantation}

Tumor histology also revealed cells with spindle morphology (Figures 6a and 6b). Expression of Ki67 demonstrated higher proliferation activity in some areas of the tumor (Figure 6c). However other areas showed scarce Ki67 positive cells (see black arrows see Figure 5n). Some tumor cells strongly expressed smooth muscle actin (Figure 6d) along with less desmin expression (Figure 6e). No expression of AE1/AE3 and S-100 protein was found (Figures $6 \mathrm{f}$ and $6 \mathrm{~g}$ respectively). Acinus-like structures were found in some areas (Figure $6 \mathrm{~h}$ ) with expression of macro-H2A.2 (Barr body) (yellow arrows in Figure 6i).

\section{Genetic microarray indicated cancer pathway activation in} INS-GFP expressing cells

Hierarchically organized tumors have been described after transplantation of transformed fibroblasts that express a cancer stem cell (CSC) marker SSEA1 [25]. The presence of differentiated and undifferentiated cells present in the tumors after INS-GFP cells transplantation prompted us to study the genes involved in formation of this tumor by genetic microarrays. Supervised analysis grouped samples into "before" and "after" differentiation protocol (before in yellow and after in blue in Supplementary Figure 2). We observed expression of pancreatic (highlighted in grey) and mesenchymal markers (Table 1) as well as genes related to cancer pathways (Supplementary Figure 3). After filtering the microarray data and using T-test between the two groups among all genes (with a fold change of at least 3 and $P$ value $\leq 0.05$ ), we found 471 different genes expressed only in differentiated cells. The pathway analysis software recognized 464 of the 471 IDs including two pathways associated with cancer.

\section{Discussion}

In the present study, we report the derivation and characterization of insulin-producing cells from mouse embryonic fibroblast cell line MMMbz [26]. Before differentiation, these cells shared some markers with MSCs and neuronal progenitor cells such as PDGFRa and nestin respectively. After differentiation, these cells expressed pancreatic- 


\begin{tabular}{|c|c|c|}
\hline Gene & $\begin{array}{l}\text { Fold change after } \\
\text { differentiation }\end{array}$ & $\mathrm{p}$-value \\
\hline Nanog & -1.23 & 0.03 \\
\hline Sox2 & -1.04 & 0.31 \\
\hline Hnf4(alpha) & 1.05 & 0.03 \\
\hline Gata4 & 1.63 & $1.73 \mathrm{E}-04$ \\
\hline Gata6 & -1.34 & $2.35 \mathrm{E}-04$ \\
\hline Nkx2.2 & 1.05 & 0.62 \\
\hline Sox9 & 2.64 & $6.85 \mathrm{E}-05$ \\
\hline Pax6 & -1.7 & 7.00E-04 \\
\hline NeuroD2 & 1.09 & 0.19 \\
\hline MafB & -2.79 & $1.39 \mathrm{E}-05$ \\
\hline Insulin 2 & 1.28 & 0.01 \\
\hline BMPR1A & -1.38 & $3.16 \mathrm{E}-04$ \\
\hline BMPR1B & -1.48 & $2.59 \mathrm{E}-05$ \\
\hline BMPR2 & -1.14 & 0.03 \\
\hline CD34 & 7.83 & 1.49E-06 \\
\hline CD44 & 2.46 & $9.32 \mathrm{E}-06$ \\
\hline Lin54 & 2.41 & $1.14 \mathrm{E}-06$ \\
\hline $\operatorname{Lin} 7 b$ & 1.16 & $9.56 \mathrm{E}-03$ \\
\hline Lin7c & 1.15 & 4.27E-05 \\
\hline Lin9 & 3.11 & $1.48 \mathrm{E}-05$ \\
\hline Lynx1(Sca-1) & 1.14 & 0.02 \\
\hline Ly6a & 1.29 & 0.04 \\
\hline Ly6c1 & 1.39 & 0.04 \\
\hline Ly6c2 & 1.39 & 0.03 \\
\hline Ly6e & -1.04 & 0.01 \\
\hline Ly6g6f & -1.12 & 0.04 \\
\hline Thy1 & -1.61 & $1.59 \mathrm{E}-03$ \\
\hline Alcam & 4.82 & $1.02 \mathrm{E}-05$ \\
\hline Cdh2 (N-Cadherin) & 1.66 & $2.15 \mathrm{E}-06$ \\
\hline Uchl1 & 1.73 & $2.27 \mathrm{E}-03$ \\
\hline Fn1 (Fibronectin) & 1.1 & 0.04 \\
\hline Itga1 & -2.35 & $1.78 \mathrm{E}-03$ \\
\hline Gnl3 & 1.3 & $6.14 \mathrm{E}-03$ \\
\hline Pdgfra & -1.92 & 7.89E-05 \\
\hline Vcam1 & 1.06 & 0.02 \\
\hline Vim (Vimentin) & 1.11 & $2.38 \mathrm{E}-04$ \\
\hline
\end{tabular}

Table 1: Pancreatic and mesenchymal markers in differentiated cells. The first two genes correspond to undifferentiated markers. The genes highlighted in grey correspond to pancreatic markers and the rest to mesenchymal or hematopoietic markers. Data were analyzed using the Ambion® WT Expression Kit For Affymetrix ${ }^{\circledR}$ GeneChip $®$ and filters were applied to pancreatic genes showing a fold change $\geq 1$ with an adjusted $p$-value $<0.05$ for each experiment condition (positive fold change indicates gene upregulation and negative fold change indicates gene downregulation).

progenitor markers (Ngn3, Nkx6.1, Ptf1a, and PDX-1) and betacell markers (PDx-1, Insulin, Nkx6.1, GLUT2, SUR1, and Kir6.2). However, after transplantation the cells developed tumors compatible with sarcoma. We introduced a reporter gene under the control of rat insulin promoter (INS-GFP) to isolate and expand insulin-producing beta-like cells after differentiation. The transfection procedure was straightforward since the cells were epithelial-like and tended to proliferate and form a monolayer. Comparable to previous reports, the percentage of insulin-producing cells in our cultures was still low (around 12\%) [4]. However, since the MMMbz cells are immortalized, the resultant beta-like cells behaved as immortalized cell line. These cells expressed GFP driven by insulin promoter for several passages. The isolation and expansion were suitable procedures to enrich the cell population; however no pure cultures were obtained after sorting [27].
Fibroblasts share many characteristics with MSCs such as the ability to differentiate into other mesodermal cell lineages as well as insulinproducing cells $[8,28]$. They also have the potential to form sarcomas in vivo [29]. Recent ontological studies suggest that fibroblasts are among the most primitive cells of adult tissues emphasizing the relationship between these cells and MSCs [11,14]. In this regard, it is attractive to consider fibroblasts as a source of cells for regenerative medicine. Although adult fibroblasts express markers of MSCs [16], our data suggest that a multipotent stem cell subpopulation can be found in embryonic fibroblasts. Adult fibroblasts acquire stem cell properties such as self-renewal and the ability to differentiate along multiple cell lineages [25]. In our model, embryonic fibroblasts expressed pancreatic progenitor and beta-cell markers after differentiation suggesting that they have the potential to form endoderm-derived lineages. Similarly, bone marrow MSCs have been reported to transdifferentiate into pancreatic islet clusters [30,31]. The presence of PDX-1 and Ngn3 in our cells after differentiation indicates that pancreatic endoderm and endocrine precursors were formed. The expression of Nkx6.1, insulin, C-peptide, PDX-1, GLUT2, Kir6.2, and SUR1 suggests that these cells underwent differentiation toward pancreatic beta cells. It is known that PDX-1 expression is necessary for beta cell function through expression of elements related to the glucose sensor system (GLUT-2, GKS, Kir6.2, and SUR1) [32-35]. Adequate function of beta-cell adenosine triphosphate (ATP)-sensitive potassium $\left(\mathrm{K}_{\text {ATP }}\right)$ channels depends on interaction between the pore-forming potassium channel subunit Kir6.2 and the regulatory subunit sulfonylurea receptor 1 (SUR1) $[34,35]$. The fact that our INS-GFP expressing cells co-expressed these markers suggests that these cells have the glucose sensor proteins of mature beta cells. STT and GCG were not expressed in vitro indicating that $\mathrm{MMMbz}$ derived insulin-producing cells are monohormonal cells. However, expression of these markers were found in vivo after transplantation suggesting that endocrine progenitors presented in the mixed population gave rise to islet cells. In our differentiated insulinproducing cells, expression of progenitor and islet-cell markers was found at early and late passages after sorting suggesting that these cells behave as a cell line and maintain their phenotype through several passages. However, chromosomal abnormalities were observed [36]. These aneuploidies were more evident after differentiation and have been related with some kinds of sarcomas [37]. Analysis of the cell cycle indicated an increased number of cells in phase $S$ at late passages (P11P20), in contrast with a lower proliferation rate (phase G0/1) at early passages (P1-P10). However, either insulin-producing cells at early or late passages had the potential for tumor-initiation, self-renewal capacity, and the ability to differentiate to some cell lineages similar to cancer stem cells (CSC) $[25,38,39]$. In support to this cancer stem cell phenotype, the microarray analysis indicated upregulation of genes such as centromere proteins $\mathrm{A}, \mathrm{M}$, and $\mathrm{N}$ (cenpa, cenpm, and cenpn), pituitary tumor-transforming gene 1 (pttg1), along with downregulation of TP53 apoptosis effector (perp) and Kruppel-like factor 15 (Klf15) after differentiation. These factors are involved in cell cycle control, differentiation, and survival and their up or downregulation has been associated to some types of cancer [40-42]. These facts suggest that a subpopulation of INS-GFP expressing cells had oncogenic potential. However, higher percentage of cells in phase G0/1 found at early passages, suggested the presence of more differentiated cells that stopped dividing. It has been described that a subpopulation of human fibroblasts can be reprogramed to multipotent cells which possess all hallmarks of CSC and can give rise to hierarchically organized tumors [25]. Our engrafted mice with INS-GFP expressing cells developed tumors consistent with this report and congruent with our findings of Ki67 in a subset of cells as well as epithelial and islet-like differentiated 
Citation: Gupta A, Kurtovic S, Ng TT, Tsuyoshi T, Narwani K, et al. (2015) Mouse Embryonic Fibroblasts Acquire Sarcomagenesis Potential after Differentiating into Insulin-Producing Cells. J Stem Cell Res Ther 5: 302. doi:10.4172/2157-7633.1000302

Page 10 of 11

structures within the tumor. In contrast with mice grafted with nondifferentiated MMMbz that never developed tumors at 30-90 days after transplantation (not shown). The rapid expansion of sarcoma cells along with deterioration of mice condition impaired us to perform functional tests such as glucose tolerance tests (GTT) and the use of streptozotocin (STZ) to induce diabetes [43]. The IHC revealed islet-like clusters that stained positive for insulin, GCG, and STT. This finding is significant because INS-GFP expressing cells maintained their differentiated phenotype in vivo and, furthermore, engrafted cells included other pancreatic endocrine cell populations apart from insulin-producing cells possibly preserving beneficial paracrine influences. The presence of cells positive for macro-H2A.2 (Barr body) in differentiated structures suggests that these cells derived from MMMbz (female origin, the host animals were all male). Furthermore, over-expression of growth factors with oncogene expression can lead to malignant transformation of cultured cells [44,45]. In addition, tumor formation has been reported after transplantation of immortalized cell lines [46]. Tumor formation is a worrisome outcome that may limit stem cell therapy. However, it may also depend on recipient characteristics $[47,48]$. We demonstrated that the cells consistently produced tumors composed of undifferentiated cells (sarcoma) and some differentiated cells (epithelial and islet-like clusters) that expressed insulin in vivo. Future studies will be necessary to identify the underling mechanisms of sarcoma formation in fibroblasts in order to obtain insulin-producing cells with no sarcomagenesis potential that can be used to treat T1DM.

\section{Acknowledgements}

We thank Patricia Lin for flow cytometry assistance. We acknowledge the funding from The Eris M. Field Endowment for Diabetes Research.

\section{Contribution Statement}

All the authors contributed in the design, data aqusition, analysis, and data interpretation. All the authors revise the content of this manuscript criticaly and approved the final version.

\section{References}

1. Hogan P, Dall T, Nikolov P (2003) Economic costs of diabetes in the US in 2002 Diabetes care 26: 917-932. [PubMed]

2. Zalzman M, Anker-kitai L, Efrat S (2005) Differentiation of Human LiverDerived, Insulin-Producing Cells toward the Bet-Cell Phenotype. Diabetes 54: 2568-2575. [PubMed]

3. Kroon E, Martinson LA, Kadoya K, Bang AG, Kelly OG, et al. (2008) Pancreatic endoderm derived from human embryonic stem cells generates glucoseresponsive insulin-secreting cells in vivo. Nat Biotechnol 26: 443-452. [PubMed]

4. D'Amour KA, Bang AG, Eliazer S, Kelly OG, Agulnick AD, et al. (2006) Production of pancreatic hormone-expressing endocrine cells from human embryonic stem cells. Nat Biotechnol 24: 1392-1401. [PubMed]

5. Shiroi A, Ueda S, Ouji Y, Saito K, Moriya K, et al. (2005) Differentiation of embryonic stem cells into insulin-producing cells promoted by Nkx2.2 gene transfer. World J Gastroenterol 11: 4161-4166. [PubMed]

6. Thomson JA, Itskovitz-Eldor J, Shapiro SS, Waknitz MA, Swiergiel JJ, et al. (1998) Embryonic Stem Cell Lines Derived from Human Blastocysts. Science 282: 1145-1147. [PubMed]

7. Lavon N, Yanuka O, Benvenisty N (2006) The effect of overexpression of Pdx1 and Foxa2 on the differentiation of human embryonic stem cells into pancreatic cells. Stem Cells 24: 1923-1930. [PubMed]

8. Choi KS, Shin JS, Lee JJ, Kim YS, Kim SB, et al. (2005) In vitro transdifferentiation of rat mesenchymal cells into insulin-producing cells by rat pancreatic extract. Biochem Biophys Res Commun 330: 1299-1305. [PubMed]

9. Rezania A, Bruin JE, Arora P, Rubin A, Batushansky I, et al. (2014) Reversa of diabetes with insulin-producing cells derived in vitro from human pluripotent stem cells. Nat Biotechnol 32: 1121-1133. [PubMed]

10. Pagliuca FW, Millman JR, Gürtler M, Segel M, Van Dervort A, et al. (2014)
Generation of Functional Human Pancreatic $\beta$ Cells In Vitro. Cell 159: 428-439. [PubMed]

11. Dominici M, Le Blanc K, Mueller I, Slaper-Cortenbach I, Marini F, et al. (2006) Minimal criteria for defining multipotent mesenchymal stromal cells. The International Society for Cellular Therapy position statement. Cytotherapy 8 : 315-317. [PubMed]

12. Horwitz EM, Le Blanc K, Dominici M, Mueller I, Slaper-Cortenbach I, et al (2005) Clarification of the nomenclature for MSC: The International Society for Cellular Therapy position statement. Cytotherapy 7: 393-395. [PubMed]

13. Haniffa MA, Collin MP, Buckley CD, Dazzi F (2009) Mesenchymal stem cells: the fibroblasts' new clothes? Haematologica 94: 258-263. [PubMed]

14. Haniffa MA, Wang X, Holtick U, Rae M, Isaacs JD, et al. (2007) Adult human fibroblasts are potent immunoregulatory cells and functionally equivalent to mesenchymal stem cells. J Immunol 179: 1595-1604. [PubMed]

15. Lysy PA, Sibille C, Najimi M, Sokal EM (2007) Human Skin Fibroblasts: From Mesodermal to Hepatocyte-Like Differentiation. Hepatology 46: 1574-1585. [PubMed]

16. Kim B, Yoon BS, Moon JH, Kim J, Jun EK, et al. (2012) Differentiation of human labia minora dermis-derived fibroblasts into insulin-producing cells. Exp Mol Med 44: 26-35. [PubMed]

17. Tateishi K, He J, Taranova O, Liang G, D'Alessio AC, et al. (2008) Generation of insulin-secreting islet-like clusters from human skin fibroblasts. Journal Biol Chem 283: 31601-31607. [PubMed]

18. Pennarossa G, Maffei S, Campagnol M, Tarantini L, Gandolfi F, et al. (2013) Brief demethylation step allows the conversion of adult human skin fibroblasts into insulin-secreting cells. Proc Natl Acad Sci 110: 8948-8953. [PubMed]

19. Lumelsky N, Blondel O, Laeng P, Velasco I, Ravin R, et al. (2001) Differentiation of embryonic stem cells to insulin-secreting structures similar to pancreatic islets. Science 292: 1389-1394. [PubMed]

20. Lock LT, Tzanakakis ES (2007) Stem/Progenitor cell sources of insulinproducing cells for the treatment of diabetes. Tissue Eng 13: 1399-1412. [PubMed]

21. Talavera-Adame D, Dafoe DC, Ng TT, Wachsmann-Hogiu S, Castillo-Henkel C et al. (2009) Enhancement of embryonic stem cell differentiation promoted by avian chorioallantoic membranes. Tissue Eng Part A 15: 3193-3200. [PubMed]

22. Talavera-Adame D, Gupta A, Kurtovic S, Chaiboonma KL, Arumugaswam V, et al. (2012) Bone Morphogenetic Protein-2/-4 Upregulation Promoted by Endothelial Cells in Coculture Enhances Mouse Embryoid Body Differentiation. Stem Cells Dev 22: 3252-3260. [PubMed]

23. Talavera-Adame D, Wu G, He Y, Gupta A, Kurtovic S, et al. (2011) Endothelia Cells in Co-culture Enhance Embryonic Stem Cell Differentiation to Pancreatic Progenitors and Insulin-Producing Cells through BMP Signaling. Stem Cell Rev 7: 532-543. [PubMed]

24. Talavera-Adame D, Ng TT, Gupta A, Kurtovic S, Wu GD, et al. (2011) Characterization of microvascular endothelial cells isolated from the dermis of adult mouse tails. Microvasc Res 82: 97-104. [PubMed]

25. luchi S, Marsch-Moreno M, Velez-DelValle C, Easley K, Kuri-Harcuch W, et al. (2006) An immortalized drug-resistant cell line established from 12-13 day mouse embryos for the propagation of human embryonic stem cells. Differentiation 74: 160-166. [PubMed]

26. Scaffidi $P$, Misteli T (2011) In vitro generation of human cells with cancer stem cell properties. Nat Cell Biol 13: 1051-1061. [PubMed]

27. Allen RK, Reddick TT, Popp DM (1998) Fluorescent activated cell sorting to isolate canine microvascular endothelial cells from adipose tissue. Methods Cell Sci 294: 285-294.

28. Pittenger MF, Mackay AM, Beck SC, Jaiswal RK, Douglas R, et al. (1999) Multilineage Potential of Adult Human Mesenchymal Stem Cells. Science 284 143-147. [PubMed]

29. Tolar J, Nauta AJ, Osborn MJ, Panoskaltsis Mortari A, McElmurry RT, et al. (2007) Sarcoma derived from cultured mesenchymal stem cells. Stem Cells 25: 371-379. [PubMed]

30. Oh S-H, Muzzonigro TM, Bae S-H, LaPlante JM, Hatch HM, et al. (2004) Adult bone marrow-derived cells trans-differentiating into insulin-producing cells for the treatment of type I diabetes. Lab Invest 84: 607-617. [PubMed] 
Citation: Gupta A, Kurtovic S, Ng TT, Tsuyoshi T, Narwani K, et al. (2015) Mouse Embryonic Fibroblasts Acquire Sarcomagenesis Potential after Differentiating into Insulin-Producing Cells. J Stem Cell Res Ther 5: 302. doi:10.4172/2157-7633.1000302

31. lanus A, Holz GG, Theise ND, Hussain MA (2003) In vivo derivation of glucosecompetent pancreatic endocrine cells from bone marrow without evidence of cell fusion. J Clin Invest 111: 843-850. [PubMed]

32. Koya V, Lu S, Sun Y, Purich DL, Atkinson MA, et al. (2008) Reversal of Streptozotocin-Induced Diabetes in Mice by A Novel Protein Transduction Domain - Based Therapy. Diabetes 57: 757-769. [PubMed]

33. Chakrabarti SK, Mirmira RG (2003) Transcription factors direct the development and function of pancreatic beta cells. Trends Endocrinol Metab 14: 78-84. [PubMed]

34. Pratt EB, Tewson P, Bruederle CE, Skach WR, Shyng SL (2011) N-terminal transmembrane domain of SUR1 controls gating of Kir6.2 by modulating channel sensitivity to PIP2. J Gen Physiol 137: 299-314. [PubMed]

35. Moritz W, Leech CA, Ferrer J, Habener JF (2001) Regulated expression of adenosine triphosphate-sensitive potassium channel subunits in pancreatic beta-cells. Endocrinology 142: 129-138. [PubMed]

36. Robertson SA, Schoumans J, Looyenga BD, Yuhas JA, Zylstra CR, et al (2005) Spectral karyotyping of sarcomas and fibroblasts derived from Ink4a/ Arf-deficient mice reveals chromosomal instability in vitro. Int J Oncol 26: 6290634. [PubMed]

37. Xiao W, Mohseny AB, Hogendoorn PCW, Cleton-Jansen AM (2013) Mesenchymal stem cell transformation and sarcoma genesis. Clin Sarcoma Res 3: 1-10. [PubMed]

38. Reya T, Morrison SJ, Clarke MF, Weissman IL (2001) Stem cells, cancer, and cancer stem cells. Nature 414: 105-111. [PubMed]

39. Clevers $H$ (2011) The cancer stem cell: premises, promises and challenges Nat Med 17: 313-319. [PubMed]

40. McGovern SL, Qi Y, Pusztai L, Symmans WF, Buchholz TA (2012) Centromere
protein-A, an essential centromere protein, is a prognostic marker for relapse in estrogen receptor-positive breast cancer. Breast Cancer Res 14: R72. [PubMed]

41. Tfelt-Hansen J, Kanuparthi D, Chattopadhyay N (2006) The emerging role of pituitary tumor transforming gene in tumorigenesis. Clin Med Res 4: 130-137. [PubMed]

42. Lin ZS, Chu HC, Yen YC, Lewis BC, Chen YW, et al. (2012) Krüppel-like facto 4, a tumor suppressor in hepatocellular carcinoma cells reverts epithelia mesenchymal transition by suppressing slug expression. PloS one 7: e43593. [PubMed]

43. Hosokawa M, Dolci W, Thorens B (2001) Differential sensitivity of GLUT1 and GLUT2-expressing beta cells to streptozotocin. Biochem Biophys Res Commun 289: 1114-1117. [PubMed]

44. Oda D, Bigler L, Mao EJ, Disteche CM (1996) Chromosomal abnormalities in HPV-16-immortalized oral epithelial cells. Carcinogenesis 17: 2003-2008. [PubMed]

45. Rao K, Bryant E, O'Hara Larivee S, McDougall JK (2003) Production of spindle cell carcinoma by transduction of $\mathrm{H}$-Ras $61 \mathrm{~L}$ into immortalized human mammary epithelial cells. Cancer Letters 201: 79-88. [PubMed]

46. Blasi E, Varesio L, Wiltrout RH (1988) Tumor formation by a murine macrophage cell line immortalized in vitro by v-raf and v-myc oncogenes. Cancer Immuno Immunother 27: 109-113. [PubMed]

47. Erdö F, Bührle C, Blunk J, Hoehn M, Xia Y, et al. (2003) Host-dependent tumorigenesis of embryonic stem cell transplantation in experimental stroke. $J$ Cereb Blood Flow Metab 23: 780-785. [PubMed]

48. Kooreman NG, Wu JC (2010) Tumorigenicity of pluripotent stem cells: biological insights from molecular imaging. J R Soc Interface 6: S753-S763. [PubMed] 